\title{
"Low Dose Spinal Anaesthesia and Its Safety in Cardiac Compromised and Highly Risk Patients"
}

\author{
Ranjan Kumar Mondal ${ }^{1 *}$, Shafiul Alam Shaheen ${ }^{2}$, Raju Ahmed ${ }^{3}$, Md. Azizul Gafur ${ }^{4}$ \\ ${ }^{1}$ Registrar \& Specialist (Anaesthesia), Ibrahim Cardiac Hospital \& Research Institute, Dhaka, Bangladesh \\ ${ }^{2}$ Associate Professor (Anaesthesia), BIRDEM General Hospital, Dhaka, Bangladesh \\ ${ }^{3}$ Associate Professor (General Anaesthesia), Ibrahim Cardiac Hospital \& Research Institute, Dhaka, Bangladesh \\ ${ }^{4}$ Professor \& Head of the Department (Anaesthesia), Ad-din Medical College, Dhaka, Bangladesh
}

\section{Article History}

Received: 11.01.2022

Accepted: 13.02 .2022

Published: 16.02 .2022

Journal homepage:

https://www.easpublisher.com

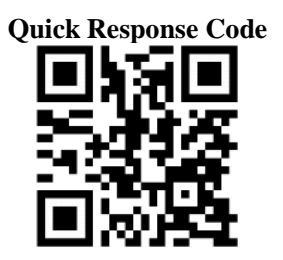

Abstract: Background: Spinal anaesthesia consists of inserting a spinal needle into the subarachnoid space and, when a free flow of cerebrospinal fluid (CSF) is obtained, injection of a solution of local anaesthetic directly into the CSF. In SA Patients is used for subumbilical surgeries but still there is a concern about its safety \& feasibility. Objective: To assess low dose spinal anaesthesia and its safety in cardiac compromised and highly risk patients. Materials and Methods: In this prospective study was conducted in the Dept. of Anaesthesia, Ibrahim Cardiac Hospital, Dhaka, Bangladesh from September 2021 to January 2022. Forty patients of aged 20-80 years were included undergoing. All patients age group American society of anesthesiology grade III-IV, with any cardiorespiratory abnormility scheduled for elective infraumbilical surgeries like ATK amputation, BTK amputation, LASER surgeries \& other Vascular surgeries ete. Patients with known contraindication to spinal anaesthesia were excluded. Relevant investigation was done e.g. haemoglobin, complete blood count, kidney function test etc. Special investigation like chest x-ray, coagulation profile only Echo, ETT if needed. On the day of surgery in preoperative room vital parameters (Heart Rate, Respiration, Blood Pressure, liver function test, Spo2) were noted \& CV line and arterial line can be done if needed. Demographic data, vital parameters, sensory -motor block characteristics \& complications were noted. Results: In our study mean and standard deviation of mean age is $43.76 \pm 10.33$ and Mean Weight $(\mathrm{Kg}) 69.7 \pm 7.4$. Out of the 40 cases, 27 were males whereas the remaining 13 were females. Forty patients of different age group, sex and weight of ASA III and IV categories were included in this study, out of which 10 patients were in age group 1825 years (5\%), 10 patients were in age group $41-50$ years $(25 \%)$ and 17 patients were in age group 51-60 years (42\%). In this study indication high perception LASER surgery (Varicose Vein) 20 (50\%), BTK amputation and ATK amputation same perception 25\%. Pre administration moderate $2.5 \%$ and severe $97.5 \%$, but Post administration Mild 38(95.0\%) and Moderate 2(5.0\%). There were no significant changes in the mean value of systolic blood pressure, diastolic blood pressure, respiratory rate, and oxygen saturation after subarachnoid block at all time period. In successful spinal cases, mean peak sensory level after 10 minute of SAB was T6.20+1.20(T4-T8) and the median was T6. Mean sensory level at the end of surgery was T8.11+1.42 (T6-T12) and the median was T8. In all successful spinal block the modified bromage scale was 3 which was seen in $90 \%$ of patients. Mean time to two segment regression was $42.91+10.72(30-70)$ min. Sensory and motor block recovery was complete in all patients Only one patient developed difficulty in breathing immediately after SAB but there was no fall in oxygen saturation \& managed with oxygen on mask with JRM circuit on spontaneous respiration. No other complications were noted such as bradycardia, hypotension, urinary retention, total spinal, \& neurological deficit. Conclusion: Spinal anaesthesia is safe feasible \& effective anaesthetic technique for subumbilical surgeries of limited duration (7080) minutes with negligible side effects.

Keywords: Spinal Anaesthesia, Infraumbilical, Complications, Hemodyamics.

Copyright $\odot 2022$ The Author(s): This is an open-access article distributed under the terms of the Creative Commons Attribution 4.0 International License (CC BY-NC 4.0) which permits unrestricted use, distribution, and reproduction in any medium for non-commercial use provided the original author and source are credited.

\section{INTRODUCTION}

Spinal anaesthesia now days increase its uses day by day in multiple fields of surgerys. Cardiac Compromised patients and patients with multiple comorbidities whom are risky for GA can be operated by low dose Spinal anesthesia safely. Spinal anaesthesia consists of inserting a spinal needle into the subarachnoid space and, when a free flow of 
cerebrospinal fluid (CSF) is obtained, injection of a solution of local anaesthetic directly into the CSF. In 1900, Bainbridge reported a case of strangulated hernia repair under spinal anaesthesia in an infant of three months [1]. After some years it fell into disuse because of the introduction of various muscle relaxants and inhalational agents and was almost unused after World War II. In the last decade, it started being advocated again by many centers due to increasing knowledge on pharmacology, safety information and availability of specialized equipment for regional anaesthetic techniques and monitoring. Spinal anaesthesia is the most preferred regional anaesthesia technique as it is easy to perform, economical and produces rapid onset of anaesthesia and complete muscle relaxation. Various adjuvants have been added to bupivacaine to shorten the onset of block and prolong the duration of block. Fentanyl, a lipophilic opioid agonist, is used as an adjuvant, which prolongs the duration of spinal block. It is universally agreed that anaesthesia of choice for lower limb surgery is subarachnoid block [2]. However spinal anaesthesia has got its own inherent complications, especially related to cardiovascular instability. Perioperative hypotension may affect postoperative recovery. The high incidence of perioperative postoperative coronary disease, increases risk of ischemia secondary to hypotension especially in critically ill patients like patients of uncontrolled diabetes mellitus, patients in congestive cardiac failure, patients with low cardiac output and ejection fraction and patients with multi organ compromise. Studies have established that opioids and local anaesthetics administered together intrathecally have potent synergistic analgesic effect, enhancing the sensory blockade without altering the degree of sympathetic blockade ensuring better hemodynamic stability [3-5]. In this population, $\mathrm{SAB}$ has been proposed as a means to reduce postoperative complications, especially apnea and postoperative respiratory dysfunction, cardiac arrest, heart failure although this utility has been questioned [6]. Spinal anaesthesia is gaining popularity but its safety, feasibility \& reliability can be established with greater use \& research.

\section{MATERIALS \& METHODS}

In this prospective study was conducted in the Dept. of Anaesthesia, Ibrahim Cardiac Hospital, Dhaka, Bangladesh from September 2021 to January 2022. Forty patients of aged 20-80 years were included undergoing. All patients age group American society of anestheslogy grade II-IV, without any cardiorespiratory abnormality scheduled for elective infraumbilical surgeries like Peripheral bypass LASER surgery of lower limb, ATK, BTK amputation were selected. Patients with known contraindication to spinal anaesthesia were excluded. All patients were kept nil by mouth for 6hrs (solid) and 3 hours (clear fluid) before anaesthesia. Relevant investigation was done e.g. haemoglobin, complete blood count, kidney function test etc. Special investigation like chest x-ray, coagulation profile Eco, ETT if needed. On the day of surgery in preoperative room vital parameters (Heart Rate, Respiration, Blood Pressure, liver function test, Spo2) were noted \& IV line was established. All emergency drugs, endotracheal tubes of appropriate sizes, Laryngoscopes, \& JRM Circuit ready. Multipara monitor for Heart rate, noninvasive Blood pressure, spo2, respiratory rate \& temperature monitoring attached. Patients of vascular surgery with cardiac diseases pulmonary hypertension (EF 30-40\%). Can be easily and safely operated by low dose spinal anesthesia (5-10 mg Bupivaccaine Heavy with 25mg fentanyl). All above baseline vital parameters were noted \& IV fluid ringer lactate $5 \mathrm{ml} \mid \mathrm{kg}$ was given over 15 minutes. After getting free flow of CSF, $0.5 \%$ hyperbaric Bupivaccaine was given intrathecally according to the weight of patients. $7.5-10 \mathrm{mg}$ Bupivaccaine with or without $25 \mathrm{mg}$ Fentanyl and height is for ATK, BTK, LASBR surgery $500 \mathrm{mg}-1000 \mathrm{mg}$ fluid is enough for surgery we should avoid over load of fluid. The end of spinal drug injection was taken as zero hour for further data recording. After injecting the drug, child was kept supine for 10 minutes. Vitals Heart Rate, systolidistolic blood pressure, Respiratory Rate, SPO2, Temperature were recorded every 1 minutes for first 10 minutes \& then every 10 minutes till the completion of surgery.

After surgery all patients were transferred to post Anaesthesia care unit for monitoring of vital signs $\&$ regression of block till the complete recovery of spinal anaesthesia \& that time was noted. Demographic data, Type \& duration of surgery, Vital parameters were noted. Requirement of supplemental sedation, local anaesthetic dose used, \& number of attempts for lumber puncture were noted. Quality of Sensory block, motor block, \& complications related to spinal anaesthesia, such as total spinal, high spinal, vomiting, shivering, urinary retention, post dural puncture headache, neurological deficit were recorded. The patients were monitored until full recovery. The data analyzed using MS Excel and IBM SPSS 19.0 (Statistical Package for the social Sciences).

\section{RESULTS}

Table-1: Patient characteristics $(\mathrm{N}=40)$

\begin{tabular}{|l|l|}
\hline Measure & Value \\
\hline $\mathrm{n}$ & 40 \\
\hline Age (years) & $43.76 \pm 10.33$ \\
\hline Weight $(\mathrm{kg})$ & $69.7 \pm 7.4$ \\
\hline Gravidity & $2(1-3)$ \\
\hline Parity & $1(0-2)$ \\
\hline
\end{tabular}

Table 1 shows the mean and standard deviation of mean age is $43.76 \pm 10.33$ and Mean Weight

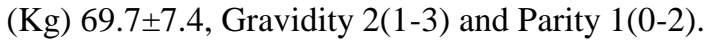


Table-3: Gender Distribution of patients studied (N=40)

\begin{tabular}{|l|l|l|}
\hline Gender & No & \% \\
\hline Male & 27 & $67.5 \%$ \\
\hline Female & 13 & $32.5 \%$ \\
\hline Total & 40 & $100 \%$ \\
\hline
\end{tabular}

Out of the 40 cases, 27 were males whereas the remaining 13 were females Table 2.

Table-2: Age distribution of patients studied $(\mathrm{N}=40)$

\begin{tabular}{|l|l|l|}
\hline Age in years & No & \% \\
\hline $18-25$ & 2 & $5.0 \%$ \\
\hline $25-40$ & 3 & $7.5 \%$ \\
\hline $41-50$ & 10 & $25.0 \%$ \\
\hline $51-60$ & 17 & $42.5 \%$ \\
\hline $61-80$ & 6 & $15.0 \%$ \\
\hline$>80$ & 2 & $5.0 \%$ \\
\hline Total & 40 & $100.00 \%$ \\
\hline
\end{tabular}

Forty patients of different age group, sex and weight of ASA III and IV categories were included in this study, out of which 10 patients were in age group
$18-25$ years (5\%), 10 patients were in age group 41-50 years $(25 \%)$ and 17 patients were in age group 51-60 years $(42 \%)$ shows in table 3 .

Table-4: Types of surgery $(\mathrm{N}=40)$

\begin{tabular}{|l|l|l|}
\hline Operations & $\mathbf{N}$ & $\mathbf{\%}$ \\
\hline ATK amputation & 10 & $25 \%$ \\
\hline BTK amputation & 10 & $25 \%$ \\
\hline LASER surgery (Varicose Vein) & 20 & $50 \%$ \\
\hline
\end{tabular}

In this study table 4 indication of high perception LASER surgery (Varicose Vein) 20 (50\%), BTK amputation and ATK amputation same perception $25 \%$.

Table-5: Intensity of pain before and after the administration of spinal analgesia $(\mathrm{N}=40)$

\begin{tabular}{|l|l|l|l|}
\hline Time point & Mild n (\%) & Moderate n (\%) & Severe n (\%) \\
\hline Pre administration & $0(0 \%)$ & $1(2.5 \%)$ & $39(97.5 \%)$ \\
\hline Post administration & $38(95.0 \%)$ & $2(5.0 \%)$ & $0(0 \%)$ \\
\hline
\end{tabular}

Table 5 shows Pre administration moderate $2.5 \%$ and severe 97.5\%, but Post administration Mild 38(95.0\%) and Moderate 2(5.0\%)

Table-6: Showing Characteristics of Subarachnoid Block.

\begin{tabular}{|l|l|}
\hline Sensory \& Motor Block Charactertics & Observations \\
\hline Mean Peak Sensory Level & T $6.20+1.20(\mathrm{~T} 4-\mathrm{T} 8)$ \\
\hline Mean Sensory level at the end of surgery & T $8.11+1.3(\mathrm{~T} 6-\mathrm{T} 12)$ \\
\hline Time to two segment Regression (min) & $42.91+10.72(30-70)$ \\
\hline Modified Bromage Score 3 & $90 \%$ \\
\hline
\end{tabular}

There were no significant changes in the mean value of systolic blood pressure, diastolic blood pressure, respiratory rate, and oxygen saturation after subarachnoid block at all time period. In successful spinal cases, mean peak sensory level after 10 minute of SAB was T6.20+1.20(T4-T8) and the median was T6. Mean sensory level at the end of surgery was T8.11+1.42 (T6-T12) and the median was T8 (Table-6).

Table-7: Vital Parameters.

\begin{tabular}{|l|l|l|l|l|l|}
\hline Timing & SBP(mmhg) & DBP(mmhg) & HR\min & RR\min & SPO2\% \\
\hline Before SAB & $85(78-96)$ & $64(66-70)$ & $98(100-120)$ & $14(13-15)$ & 100 \\
\hline After Premedication & $92(80-97)$ & $62(63-72)$ & $110(98-135)$ & $13(11-14)$ & 99 \\
\hline 5minutes after SAB & $90(80-95)$ & $67(60-70)$ & $105(116-128)$ & $12(10-13)$ & 100 \\
\hline 10 minutes after SAB & $86(78-93)$ & $64(62-72)$ & $100(97-120)$ & $10(9-11)$ & 100 \\
\hline 20 minutes after SAB & $84(76-94)$ & $59(60-66)$ & $94(92-1190$ & $14(12-16)$ & 100 \\
\hline 60 minutes after SAB & $87(80-94)$ & $62(63-72)$ & $89(90-103)$ & $14(12-16)$ & 100 \\
\hline PACU ROOM & $88(77-96)$ & $66(62-72)$ & $95(99-108)$ & $13(12-14)$ & 100 \\
\hline
\end{tabular}


In all successful spinal block the modified bromage scale was 3 which were seen in $90 \%$ of patients. Mean time to two segment regression was $42.91+10.72(30-70) \mathrm{min}$. Sensory and motor block recovery was complete in all patients. Heart rate showed increases to $110(11.2 \%)$ after $5 \mathrm{~min}$ of subarachnoid block as compared to baseline. This can be due to glycopyrolate \& ketamine which were used for premedication \& before giving SAB. However afterwards mean heart rate showed no significant change from baseline. Only one patient developed difficulty in breathing immediately after SAB but there was no fall in oxygen saturation \& managed with oxygen on mask with JRM circuit on spontaneous respiration (Table-7).

\section{Table-8: Number of patients Showing Intraoperative} complications.

\begin{tabular}{|l|l|}
\hline Complications Noted & Number of Patients \\
\hline Difficulty in Breathing & 1 \\
\hline Shivering & 2 \\
\hline Nausea \& Vomiting & 1 \\
\hline
\end{tabular}

Difficulty in Breathing was noted in one patient $(2.5 \%)$ who was managed with oxygen on mask and patient get stable in 10 minutes. Shivering was noted in two patients $(5 \%)$ and treated with IV pentazocine $0.2 \mathrm{mg} \mid \mathrm{kg}$. Nausea \& vomiting observed in one patient $(2.5 \%)$ and treated with IV ondansterone $0.1 \mathrm{mg} \mathrm{kg}$. No other complications were noted such as bradycardia, hypotension, urinary retention, total spinal, $\&$ neurological deficit (Table-8).

\section{DISCUSSION}

This prospective study was done to evaluate the perioperative haemodynamic changes, feasibility \& safety of spinal anaesthesia. As compared to general anaesthesia decreased stress response \& recovery is very fast following spinal anaesthesia [7]. In our study mean and standard deviation of mean age is $43.76 \pm 10.33$ and Mean Weight $(\mathrm{Kg}) 69.7 \pm 7.4$. Forty patients of different age group, sex and weight of ASA III and IV categories were included in this study, out of which 10 patients were in age group $18-25$ years $(5 \%)$, 10 patients were in age group 41-50 years $(25 \%)$ and 17 patients were in age group 51-60 years (42\%) shows in our study. In this study indication of high perception LASER surgery (Varicose Vein) 20 (50\%), BTK amputation and ATK amputation same perception $25 \%$. This is advantageous and minimizes hemodynamic changes associated with conventional spinal anaesthesia. It also enables faster recovery and early discharge [8-10]. It is much useful in critically ill patients, patients with cardiac failure, low ejection fraction etc, in whom the systemic vascular resistance (SVR) and blood pressure may decrease more [11, 12] than in patients with good left ventricular function 10. Previous studies showed that hypotension after spinal block could be minimized by using of small dose of local anesthetics [13]. In left lateral position after cleaning \& draping of lumber area, with $25 \mathrm{~g}$ hypodermic needle lumber puncture was done at L3-L4 or L4-L5/L5-S1 space \& with clear free flow of CSF $0.5 \%$ heavy Bupivaccaine was injected according to the weight of SA patients. During lateral position the neck was in extension as cervical flexion may obstruct the airway during the procedure. After that child was kept supine \& intraoperatively children was kept sedated with $\mathrm{O} 2$ and sevoflurane on mask with JRM circuit on spontaneous respiration intermittently when they were moving the upper part of body. Sedative effects of SAB itself have also been documented in the literature. Hermanns et al. [14] conducted the study to evaluate the sedation during spinal anaesthesia in infants. Meantime two segment regression was $42.91+10.72$ (30-70) min. Since the level of surgery was below T10in all the patients adequate dermatome level was present until the end of surgery. This restricts the use of SAB in surgeries of duration 60-70 minutes. The most common complications in our study observed were Shivering. Difficulty in Breathing was noted in one patient $(2.5 \%)$ who was managed with oxygen on mask and patient get stable in 10 minutes. Shivering was noted in two patients $(5 \%)$ and treated with IV pentazocine $0.2 \mathrm{mg} \mid \mathrm{kg}$. Nausea \& vomiting observed in one patient $(2.5 \%)$ and treated with IV ondansterone $0.1 \mathrm{mg} l \mathrm{~kg}$. No other complications were noted such as bradycardia, hypotension, urinary retention, total spinal, $\&$ neurological deficit. One patient developed difficulty in breathing immediately after SAB \& was managed with $\mathrm{O} 2$ on mask with JRM circuit on spontaneous respiration gets cured within 10 minutes. No other complications noted such as total spinal, hypotension, bradycardia, urinary retention \& any neurological deficit. Modification was the primary cause of decrease cardiac output especially in patients with low ejection fraction [15]. Patients with low cardiac index who underwent spinal block with low dose of local anaesthetic showed less decrease in mean arterial pressure because small dose of local anaesthetic blocked sympathetic system less than traditional dose. Lidocaine was used as drug for spinal anaesthesia in past. It is associated with permanent and transient neurotoxicity. This led to exploration of adapting the longer acting spinal bupivacaine to ambulatory anaesthesia [16-18]. Conventional large dose bupivacaine may delay the recovery of motor function, may cause urinary retention, hemodynamic instability, leading to delayed discharge. So the interest was increased to use small doses of bupivacaine. Fentanyl is a lipophilic opioid usually used as an adjunct to local anaesthetics for enhancement of analgesia without intensifying motor and sympathetic block during spinal anaesthesia. There are no associated side effects except mild Pruritis. 


\section{CONCLUSION}

In our experience no gross intraoperative hemodynamic changes observed \& also no permanent adverse complications occurred. The technique of spinal anaesthesia provides a good alternative to general anaesthesia in patients with increased general anaesthesia related risks (Malignant Hyperthermia, Difficult airway, Laryngospasm, delayed recovery etc), $\&$ for patients undergoing lower abdominal or lower extremity surgery, lasting less than 60-70 minutes of duration. Economically also spinal anaesthesia is very cheap compared to general anaesthesia. Since our number of study patients were very less this topic requires large number of studies of paediatric patients for further confirming our observations.

\section{REFERENCES}

1. Fortuna, A. (1967). Caudal analgesia; A simple and safe technique in pediatric surgery. Br J Anesth, 39, 156-159.

2. Karpel, E., Marszołek, P., Pawlak, B., \& Wach, E. (2009). Effectiveness and safety of unilateral spinal anaesthesia. Anestezjologia Intensywna Terapia, 41(1), 33-36.

3. Fernandez-Galinski, D., Rue, M., Moral, V., Castells, C., \& Puig, M. M. (1996). Spinal anesthesia with bupivacaine and fentanyl in geriatric patients. Anesthesia \& Analgesia, 83(3), 537-541.

4. Edward Morgan, G. (2002). Jr. Geraitric Anaesthesia, Clinicalanaesthesiology, 3 edn 2002 pg 875-879.

5. Priebe, H.J. (2000). The aged cardiovascular risk patient. BJA 85(50: 763-778.

6. Somri, M., Gaitini, L. A., Vaida, S. J., Malatzkey, S., Sabo, E., Yudashkin, M., \& Tome, R. (2003). The effectiveness and safety of spinal anaesthesia in the pyloromyotomy procedure. Pediatric Anesthesia, 13(1), 32-37.

7. Goyal, R., Jindal, K., Baj, B., Singh, S., Kumar, S. (2008). Pediatric spinal anesthesia. Indian $J$ Anaesth, 52; 264-70.

8. Enk, D., Prien, T., Van Aken, H., Mertes, N., Meyer, J., \& Brüssel, T. (2001). Success rate of unilateral spinal anesthesia is dependent on injection flow. Regional anesthesia and pain medicine, 26(5), 420-427.

9. Fanelli, G., Borghi, B., Casati, A., Bertini, L., Montebugnoli, M., \& Torri, G. (2000). Unilateral bupivacaine spinal anesthesia for outpatient knee arthroscopy. Canadian

Journal

of

Anesthesia, 47(8), 746-751.

10. Kuusniemi, K. S., Pihlajamäki, K. K., \& Pitkänen, M. T. (2000). A low dose of plain or hyperbaric bupivacaine for unilateral spinal anesthesia. Regional Anesthesia \& Pain Medicine, 25(6), 605-610.

11. Gullberg, B., Johnell, O., \& Kanis, J. A. (1997). World-wide projections for hip fracture. Osteoporosis international, 7(5), 407-413.

12. Beaupre, L. A., Jones, C. A., Saunders, L. D., Johnston, D. W. C., Buckingham, J., \& Majumdar, S. R. (2005). Best practices for elderly hip fracture patients. Journal of general internal medicine, 20(11), 1019-1025.

13. Ben-David, B., Frankel, R., Arzumonov, T., Marchevsky, Y., \& Volpin, G. (2000). Minidose bupivacaine-fentanyl spinal anesthesia for surgical repair of hip fracture in the aged. The Journal of the American Society of Anesthesiologists, 92(1), 66.

14. Hermanns, H., Stevens, M. F., Werdehausen, R., Braun, S., Lipfert, P., \& Jetzek-Zader, M. (2006). Sedation during spinal anaesthesia in infants. BJA: British Journal of Anaesthesia, 97(3), 380-384.

15. Sen, S., Aydin, K., \& Discigil, G. (2007). Hypotension induced by lateral decubitus or supine spinal anaesthesia in elderly with low ejection fraction undergone hip surgery. Journal of clinical monitoring and computing, 21(2), 103-107.

16. May, L. G., Bennett, A., Lane, A. L., Futch, E. D., Lynn-Schoomer, M., \& Gregory, R. (1949). Effect of high spinal anesthesia on the cardiac output of normal and hypertensive patients. The American Journal of Medicine, 7(2), 251-252.

17. Valanne, J. V., Korhonen, A. M., Jokela, R. M., Ravaska, P., \& Korttila, K. K. (2001). Selective spinal anesthesia: a comparison of hyperbaric bupivacaine $4 \mathrm{mg}$ versus $6 \mathrm{mg}$ for outpatient knee arthroscopy. Anesthesia \& Analgesia, 93(6), 13771379.

18. Butterworth, J. F., \& Strichartz, G. R. (1990). Molecular mechanisms of local anesthesia: a review. Anesthesiology, 72(4), 711-734.

19. Breebaart, M. B., Vercauteren, M. P., Hoffmann, V. L., \& Adriaensen, H. A. (2003). Urinary bladder scanning after day-case arthroscopy under spinal anaesthesia: comparison between lidocaine, ropivacaine, and levobupivacaine. British Journal of Anaesthesia, 90(3), 309-313.

Cite this article: Ranjan Kumar Mondal, Shafiul Alam Shaheen, Raju Ahmed, Md. Azizul Gafur (2022). "Low Dose Spinal Anaesthesia and Its Safety in Cardiac Compromised and Highly Risk Patients". EAS J Anesthesiol Crit Care, 4(1), 4-8. 